\title{
Locomotion and proliferation of glioblastoma cells in vitro: statistical evaluation of videomicroscopic observations
}

\author{
Balázs Hegedüs ${ }^{1}$ M.Sc., András Czirók ${ }^{1}$ M.Sc., Ilona Fazekas ${ }^{2}$ M.D. Ph.D., \\ Tamás Bábel ${ }^{2}$ M.D., Emília Madarász ${ }^{3}$ M.Sc. Ph.D. \& \\ Tamás Vicsek ${ }^{1}$ M.Sc. Ph.D. University Professor \\ ${ }^{1}$ Department of Biological Physics, Eötvös University, Budapest, Hungary \\ 2 National Institute of Neurosurgery, Budapest, Hungary \\ ${ }^{3}$ Institute of Experimental Medicine, Hungarian Academy of Sciences, Budapest, Hungary \\ Corresponding and reprint author: Balázs Hegedűs \\ Department of Biological Physics \\ Eötvös University \\ H-1117 Budapest \\ Pázmány Péter sétány $1 \mathrm{~A}$ \\ Hungary \\ Tel: (36)-1-3722795 \\ Fax: (36)-1-3722757 \\ e-mail: hebal@angel.elte.hu
}

Supports: Gedeon Richter Pharmaceutical Company (Richter 216/97/KK)

Ministry of Education (FKFP 0203/1997)

Hungarian Science Foundation (OTKA T25719, OTKA T019299)

Running head: Locomotion and proliferation of glioblastoma cells

Key words: glioblastoma, videomicroscopy, cell migration, proliferation

\section{ABSTRACT}

Long-term videomicroscopy and computer-aided statistical analysis were used to determine some characteristic parameters of in vitro cell motility and proliferation in three established cell lines derived from human glioblastoma tumors. Migration and proliferation activities were compared among the three cell lines since these are two features of tumor cells that strongly influence the progression of cancer.

Cell proliferation in sub-confluent cultures were evaluated by calculating the growth rate of the number of cells and the distribution of the cell-cycle times in a given microscopic field. In these parameters no significant difference was observed among the cell lines regardless to the number of passages.

Studies on cell locomotion revealed strong fluctuations in time and exponential distribution of cell velocities. In spite of the fluctuations, both the distribution profile and the average velocity values were reproducibly characteristic to each cell line investigated.

The results on these dynamical parameters of cell locomotion were compared to pathological data obtained by traditional methods. The data indicate that the analysis of cell motility provides more specific information and is potentially useful in diagnosis.

\section{INTRODUCTION}

In order to provide appropiate methods for the characterization of the large variety of human brain tumors, reproducible and quantitative models are needed. Then, one can carry out a characterization of the dynamics of tumor cells providing substantial information supplementing the results of such statical methods as histology or molecular genetics. For example, in vitro studies on the cell cycle and motility of tumor derived cells could provide relevant information for the diagnosis and the estimation of the progression of the cancer. The correlation between tumor 
malignancy and increased migration activity of glioma cells had been demonstrated by in vivo and in vitro experiments using rat brain xenografts [1,11] or radial dish assays [4,5]. In addition, studies of cell proliferation using either proliferation-marker antibodies in tissue sections or flow cytometry of tumor- derived cell cultures have also demonstrated that the growth fraction of the specimen often correlates with the malignancy of the tumor [8, 10].

In several cases tumor recurrence is originated by a minor subpopulation of highly migratory cells which were not removed surgically with the bulk tumor. Thus, the detection of such subpopulations and the estimation of their infiltration depth is essential for postoperational treatments. However, fluctuations in locomotion or proliferation generate difficulties in the characterization of the heterogeneity of a tumor specimen; according to early studies a strong variation is present in the intermitotic times even within a single-cell derived population [18]. Fluctuations dominate the motility of single cells as well [9,13,7]. The classical methods assaying cell division frequency or cell motility cannot distinguish between a fluctuating but homogeneous population and an inhomogeneous population, thus their prognostic value is rather limited regarding heterogeneity [10]. To reveal details about heterogeneity and subpopulations in vitro experiments and careful statistical analyses are required.

Simultaneous and automatized observation of the mitotic and locomotory activity of a large number of cells during a long time interval can provide a direct way to overcome such difficulties.

We describe here a novel long-term videomicroscopic system together with a computer-aided statistical analysis to quantify the in vitro behavior of cells. With this method we compared three established glioblastoma cell lines derived from three patients. Glioblastoma is a common and highly malignant (WHO Grade IV.) tumor that develops in late adult life and generally located in the cerebral hemispheres. These tumors contain motile and invading cells, frequently causing rapid recurrence after surgical resection [15]. In some cases the migration of these cells lead to the progress of the disease even without the formation of notable mass effect [19].

While our studies revealed a rather similar proliferation activity in all investigated cell lines, a reproducible and significant difference was found in the locomotory activity of the cells. Due to the large number of individually tracked cells the question on the homogeneity of cell motion and proliferation of the cell populations could be also addressed. By appropriate automatization the complete analysis can be completed within 4 or 5 days after processing the surgical specimen to one-cell suspension, providing a new tool for diagnostical purposes.

\section{MATERIALS AND METHODS}

\section{A. Diagnosis of human brain tumors}

The surgical specimens were obtained during craniotomies for resection of 3 hemispherical primary brain tumor. The bigger part of the specimen was evaluated by routine histopathology, including staining with hematoxylin and eosin and immunohistochemical staining for GFAP expression. Specimens were graded according to the WHO classifications [12] at the Histopathological Department of National Institute of Neurosurgery.

\section{B. Establishment of human brain tumor cell lines}

Part of the specimen was used for establishing the cell lines. The samples were washed by Minimal Essential Medium (Sigma) containing gentamycin (Chinoin) and Fungizone (Gibco). After removing the vessels, the samples were minced and then triturated with a Pasteur-pipette. The primary tissue was seeded into Leighton culture flask on Bellco-slide or into Steriline culture flask in Dulbecco's MEM (Sigma) with 20\% FCS (Gibco). According to our procedure the cultures are not one-cell derived. The passages were performed with $0.25 \%$ trypsin and cells transferred to Greiner tissue culture flasks. Cells were maintained in DMEM (Sigma) with 10\% FCS, $40 \mu \mathrm{g} / \mathrm{ml}$ gentamycin and $5 \mu \mathrm{g} / \mathrm{ml}$ Fungizone, at $37^{\circ} \mathrm{C}$ in a humidified $5 \% \mathrm{CO}_{2}$ atmosphere. Cells were stored in $10 \%$ DMSO (Sigma) DMEM solution in liquid nitrogen for later use.

\section{Immunocytochemical staining for GFAP in the cultures}

The cultured cells' glial origin was indicated by the presence of glial fibrillary acidic protein (GFAP). Cells cultured on slides were fixed with Zamboni-solution for 60 minutes at room temperature. Then incubated as follows: 3 times 10 minutes in PBS (Phosphate Buffered Saline), 20 minutes 15\% human albumin in PBS (Human), 30 minutes with mouse anti-GFAP antibodies (High Performance, Biogenex) in a humidified chamber, 20 minutes biotin-conjugated antimouse immunoglobulin (Multilink Stravigen, Biogenex), 20 minutes peroxidase-conjugated streptavidin (Biogenex). 
Slides were developed with DAB $\left(2,5 \mathrm{mg} \mathrm{DAB}+5 \mathrm{ml} \mathrm{PBS}+50 \mu \mathrm{l} 1 \% \mathrm{H}_{2} \mathrm{O}_{2}\right)$ under microscopic control. Controls were performed without the primary antibodies.

\section{Long-term videomicroscopy}

$10^{5}$ cells, counted in haemocytometer, were plated in $35 \mathrm{~mm}$ TC-dishes (Greiner) with $2 \mathrm{ml}$ medium (DMEM (Sigma) with $10 \%$ FCS (Gibco)). Cell cultures were kept in a mini-incubator - providing $37^{\circ} \mathrm{C}$ in a humidified $5 \%$ $\mathrm{CO}_{2}$ atmosphere - attached to the powered stage of an inverted phase-contrast microscope (Zeiss Televal-1)(Fig 1). Images of 3-6 neighbouring microscopic fields were taken in every 5 minutes during a 3-day long period, with $10 \times$, $20 \times$ or $40 \times$ objectives using a CCD camera (JVC KY-F30B) connected directly to the frame grabber card (Matrox Meteor, Matrox Electronic Systems LTD, Canada) of a PC (running under LINUX operating system).

\section{E. Cell positions and trajectories}

To determine the position $\left(\overrightarrow{x_{i}}\right)$ of the individual cells, the geometrical center of each cell was tracked manually in every 4 th image (i.e., in every 20 minutes in real time). The difference in the location of a given cell was considered as a migratory segment. Trajectories were constructed from these segments.

\section{F. Duplication time}

Using the database of cell positions, the total number of cells in a given microscopic field $(n)$ was determined. The growth of cell number was found to be approximately exponential in each investigated culture, i.e., $n \sim e^{\alpha t}$. Based on a least square-fit of $\alpha$, the duplication time, $\tau$, was calculated as $\tau=(\ln 2) / \alpha$.

\section{G. Cell-cycle time and non-proliferating cells}

All cell divisions during the observation period were identified resulting a data base containing the corresponding mother and daughter cells. The cell cycle length $\left(\tau_{0}\right)$ of a given cell was then determined as the time elapsed between two consecutive cell divisons.

We denote by $\nu$ the rate at which non-proliferating cells appear in the culture. It was calculated in two steps. First we determined $N$, the number of proliferating cells by the criteria that both their birth and subsequent mitosis was recorded and their birth occured more than 30 hours before the end of the recording. Then $N_{*}$, the number of suspected non-dividing cells was calculated. These cells were selected using the following criteria: (i) lack of observed mitosis during the entire recording period, and (ii) being tracked for at least 30 hours following their birth. Then, $\nu$ was calculated as $\nu=N_{*} /\left(N_{*}+N\right)$.

Note, that there are two sources of systematic errors in this procedure. On one hand, when calculating $N_{*}$, cells may be included which do divide, but their cell cycle length is longer than the time period during the culture was observed. On the other hand, we did not include in $N_{*}$ cells which do not divide, but we could not track them for longer than 30 hours because they left the field of observation. Taking into account that during a 30-hour period approximately $10 \%$ of the cells migrated out of the observed area, and (based on the empirical distribution of the cell-cycle times $) \approx 20 \%$ of the dividing cells have longer cell cycle than $30 \mathrm{~h}$, we estimate the relative error of $\nu$ to be $10 \%$.

Assuming that after each division a $\nu$ th portion of daughter cells become unable to further proliferate, the size of the cell population $(n)$ after the $k$ th complete set of cell division - denoted as $n\left(k \tau_{0}\right)$ - is given by

$$
\log n\left(k \tau_{0}\right) \approx k \log 2(1-\nu)+\text { const. }
$$

Thus based on this simple calculation, the relation

$$
\tau_{0} \log 2=\tau \log 2(1-\nu)
$$

is expected to hold among the independently measurable parameters $\tau, \tau_{0}$ and $\nu$. 


\section{H. Cellular velocities}

The velocity, $v_{k}(t)$, of a given cell $k$ was calculated as the translocation of its geometrical center during a given time interval, $\Delta t$, i.e.,

$$
v_{k}(t)=\left|\frac{\vec{x}_{k}(t+\Delta t)-\vec{x}_{k}(t)}{\Delta t}\right| .
$$

$\Delta t$ was chosen to be $1 \mathrm{~h}$, since during this time interval the displacement of the cells were typically larger than the cell size, thus the relative error of $v_{k}(t)$ resulting from the tracking procedure was reduced. Nevertheless, during one hour (as our data show) the fluctuations in cell motility were not yet averaged out.

To characterize such a fluctuating quantity as the cell locomotion activity we determined the $F(v)$ cumulative distribution function. $F(v)$ gives the probability of the event that the velocity of a randomly selected cell at a given time is less than $v$. Since the relative error of the small cell displacements is high due to the manual tracking procedure, velocities less than $5 \mu \mathrm{m} / \mathrm{h}$ were discarded in the analyses. The $F(v)$ empirical distribution function was fitted by an exponential distribution [7] as

$$
F(v)=1-\exp \left(-v / v_{0}\right)
$$

where $v_{o}$ is a fitting parameter being equal to the mean velocity if (4) is exact.

As another way to characterize the motility of the cells, the empirical average velocity of the culture, $V$, was calculated as

$$
V=\frac{\sum_{k} \sum_{i} v_{k}\left(t_{i}\right)}{\sum_{k} \sum_{i} \delta_{k}\left(t_{i}\right)}
$$

where $\delta_{k}\left(t_{i}\right)$ is 1 , if the $k$ th cell is in the visual field in the $t_{i}$ moment, otherwise 0 .

\section{RESULTS}

\section{A. Histological description of tumors and cell lines}

The main features of the cell lines are given in Table 1. The routine histology of the tumor specimens concerning WHO classification revealed glioblastoma. All three sections showed hypercellularity, pleomorphism, vascular proliferation and necrosis. The HA and HC specimens (detailed in Table 1) were classified as glioblastoma multiforme. In the HB specimen some areas were dominated by multinucleated giant cells and the invasion of lymphoid cells was observed. Thus HB was classified as giant cell variant of glioblastoma.

The cultures were morphologically characterized according to Bigner [2]. Usually the HA-derived cells had two or three processes and the formation of filopodia was quite frequent. The HB culture's cells were mostly elongated, had more processes and the formation of filopodia and lamellipodia with ruffling edges was exceedingly intensive. Both morphology was described as fibroblastic. In contrast, even the subconfluent HC cultures showed typical epithelial morphology with the general absence of cellular processes. The cells formed preferentially a monolayer, though cells could crawl over each other. During cultivation multinucleated monstrocells were observed in all the three lines. On the time-lapse records cell divisions into three daughter cells were also observed occasionally. In most of these cases the resulting daughter cells seemed to perform normal mitoses later on.

\section{B. Cell proliferation}

The number of cells in a given microscopic field grew exponentially after an initial lag phase of 15-20 hours (Fig 2). Based on these data the cell duplication times were determined (Tab 2). No significant differences were found in the duplication time of the various cell lines: each culture could be characterized by $\tau=38 \pm 4$ hour.

The cell number in a given microscopic field changed because of cell divisions and the migration of the cells. According to our observations the net current of migration was approximately zero, so the increase of cell number was basically determined by the ratio of dividing cells and the duration of their cell-cycle.

Continuous observation of the cultures allowed to determine the cell-cycle time $\left(\tau_{0}\right)$ of individual cells as well. The empirical distribution functions of the cell cycle lengths were similar in all the three cell lines investigated (Fig 
3). In fact, based on this amount of data the distributions could not be distinguished based on a Wilcoxon test (with $\mathrm{p}<0.05$ ). The average cell-cycle time was found to be $25.6 \pm 6.2$ hours. The difference between the average cell-cycle time and the duplication time of the cell population can be explained by the presence of non-dividing cells. The proportion of these cells, $\nu$, was found to be $32 \pm 5 \%$ (Table 2). According to relation (2) this proportion was determined by average cell-cycle time $\left(\tau_{0}\right)$ and duplication time $(\tau)$ as $34 \%$. Thus, relation (2) holds within error for the rate of arising of non-proliferating cells, average cell-cycle time $\left(\tau_{0}\right)$ and duplication time $(\tau)$.

To investigate the role of hereditary factors in the determination of cell-cycle time the correlation between parent and daughter cells was studied (Fig 4). The scattering of data indicates uncorrelated variables, it means that the duration of cell-cycle is not influenced by the parent cell's cell-cycle time.

\section{Cell locomotion}

The dynamics of cell shape can be qualitatively observed and characterized using the long term time-lapse records(Fig 5). The videomicroscopic images showed the rich dynamics of the formation of lamellipodia and filopodia. The intensity of ruffling edge formation correlated with the motility of cells [13]. As expected, the epithelial [2] HC cells displayed the lowest motility and the HB cells were more motile than the other fibroblastic [2] HA cell line.

The analysis of the pathways of individual cells revealed that in subconfluent cultures the direction of cell movement is random and disordered (Fig 6a). However, at high cell densities the HB cell line displayed a rather ordered collective migration (Fig 6b).

In all of the three cell lines the cell velocities were highly fluctuating as demonstrated in Fig 7 .

The $F(v)$ cumulative distribution functions are shown in Fig 8. Both the distribution functions and the average velocities of the culture $\left(V\right.$ and $\left.v_{0}\right)$ were different among the three cell lines but within error reproducible for each individual cell line (Table 3).

\section{Population homogeneity}

To understand the relation between velocity distribution function and the homogeneity of locomotory activity of the cell population further statistical analysis is required. The velocity distributions described by (4) were found for relatively large $(\approx 100$ cells $)$ populations. On the level of individual cells the exponential behaviour (4) can be interpreted in two ways: (i) The culture is inhomogeneous, i.e., slower and faster cells can be distinguished on the bases of well preserved phenotypic properties. In this case the exponential $F(v)$ distribution can reflect the ratio of the slow and fast cells in the culture, while the velocity fluctuations of the individual cells can show an arbitrary distribution. (ii) If the culture is homogeneous, then almost all cells exhibit the same distribution of velocity fluctuations, i.e., $F_{i}(v) \approx F(v)$ holds for each cell $i$, where $F_{i}(v)$ denotes the velocity distribution function of the cell $i$. In this scenario the time-averaged velocity $\left\langle v_{i}(t)\right\rangle$ of each cell would be the same if we could calculate the time averages over an infinitely long time. Since the time averages are calculated over a finite time $T$ only, for the distribution of the average velocities we can expect a Gamma distribution with a parameter $s=T / t_{0}$, where the correlation time of the process is denoted by $t_{0}$ [7].

We used the distribution function of the average velocity of individual cells (averaged over the entire observation period) to characterize the inhomogeneity within the cell lines. In all cases the average velocity of the cells showed a gamma distribution indicating the homogenity of the cell population (Fig. 9.). However, if applying the same kind of analysis on a cell position data base in which cells from different cell lines were mixed, a significant deviation from the gamma distribution can be observed (shown in the insert of Fig. 9.).

\section{DISCUSSION}

The comparison of classical morphological data and the dynamical properties in the three glioblastoma cell lines gave some unexpected results. In spite of the different origin and different passage-levels of the investigated lines significant alterations in the in vitro proliferating potential were not revealed. Both the cell-cycle time and the percentage of dividing cells under the same culture conditions were found equal in the three different glioblastoma lines. The cellcycle time measured in our cultures did not differ from the doubling time of normal primary fibroblasts from human skin [3]. The variability of the cell-cycle time of individual cells seems to be independent from inheritable factors and might be best explained by the stochastic activity of the cells. 
The experimental verification of Eq. (2) suggests that the non-dividing cells did not belong to an initial subpopulation in the culture but arose continuously during proliferation. The considerable proportion of these cells may indicate that defective mitoses are abundant in the cell culture. The cause of this phenomenon can be the genetical instability of tumor cells which has been recently demonstrated [3].

Although the in vitro cell motility is a highly stochastic process regarding the direction of the movement or the fluctuation of the velocity of an individual cell, the locomotory activity of the cell lines have some quantitative properties that can be interdependent with the morphology of the cultured cells. The cell lines with fibroblastic morphology performed higher locomotory activity. Reproducible and significant difference was found in the locomotion of the cells among the three investigated glioblastoma cell lines.

The HB case can illustrate that classical studies are not always satisfying in the forecast of the disease course. In spite of the diagnosis as a giant cell variant, which is commonly known as a less malignant type of glioblastoma, and the powerful presence of immune response, the tumor was fatally renewed within 4 month. It can be supposed that the fast and strong recurrence was due to the highly motile cells that invaded the surrounding tissue and were not removed surgically.

Our data were obtained on established cell lines after multiple passages, in this way these cultures may not reflect entirely the properties of the cells of the investigated tumors. With similar preparations the evaluation can be performed on primary cultures with no passages as well. Investigations of in vitro dynamic behavior of primary cell cultures from surgical specimens can complement classical diagnostic methods. Although during culturing an inevitable selection takes place, some of the initial features or even heterogenity of the tumor tissue may be reflected in the cell cultures. If such analysis can be carried out within a short period of time, it can help to choose the most appropriate postoperative therapy in each individual case.

\section{ACKNOWLEDGEMENTS}

We are indebted to Felícia Slowik for the diagnosis. We thank Zoltán Csahók and Ottó Haiman for the technical support and Antalné Kerekes for the maintainance of the cultures.

[1] Bernstein JJ, Goldberg WJ, Laws ER Jr: Human malignant astrocytoma xenogtrafts migrate in rat brain: a model for central nervous system cancer research J Neurosci Res 22:134-143, 1989

[2] Bigner DD et al.: Heterogeneity of Genotypic and Phenotypic Characteristics of Fifteen Permanent Cell Lines Derived from Human Gliomas J Neuropathol Exp Neurol 40: 201-227, 1981

[3] Cahill DP et al.: Mutations of mitotic checkpoint genes in human cancers Nature 392:300-333, 1998

[4] Chicoine MR, Silbergeld DL: Assessment of brain tumor cell motility in vivo and in vitro. J Neurosurgery 82: 615-622, 1995

[5] Chicoine MR, Silbergeld DL: Mitogens as motogens J Neurooncol 35: 249-257, 1997

[6] Chicoine MR, Silbergeld DL: The in vitro motility of human gliomas increases with increasing grade of malignancy. Cancer 75: 2904-9, 1995

[7] Czirók A, Schlett K, Madarász E, Vicsek T: Exponential Distribution of Locomotion Activity in Cell Cultures Phys Rev Lett 81:3038-3041, 1998

[8] Deckert M, Reifenberger G, Wechsler W: Determination of proliferative potential of human brain tumors using the monoclonal antibody Ki-67 J Cancer Res Clin Oncol 115:179-188, 1989

[9] Dunn GA and Brown AF: A Unified Approach to Analysing Cell Motility J Cell Sci Suppl 8: 81-102, 1987

[10] Hoyt JW, Gown AM, Kim DK, Berger MS: Analysis of proliferative grade in glial neoplasms using antibodies to the Ki-67 defined antigen and PCNA in formalin fixed, deparaffinized tissues. J Neurooncol 24:163-169, 1995

[11] Huang P, Allam A, Taghian A: Growth and metastatic behavior of five human glioblastoma compared with nine other histological types of human tumor xenografts in SCID mouse. J Neurosurgery 83:308-315, 1995

[12] Kleihues P, Burger PC, Scheithauer BW: Histological Typing of Tumours of the Central Nervous System World Health Organization, International Histological Classification of Tumours Springer-Verlag: Berlin, Heidelberg, 1993

[13] Lauffenburger DA, Horowitz AF: Cell Migration: A Physically Integrated Molecular Process Cell 84:359-369, 1996

[14] Müller W, Slowik F, Firsching R, Afra D, Sanker P: Contribution to the problem of giant cell astrocytomas. Neurosurg Rev 10:213-219, 1987

[15] Nazzaro JM, Neuwelt EA: The role of surgery in the management of supratentorial intermediate and high-grade astrocytomas in adults. J Neurosurgery 73:331-344, 1990 
[16] Onda K, Davis RL, Shibuya M, Wilson CB, Hoshino T: Correlation between the Bromodeoxyuridine Labeling Index and MIB-1 and Ki-67 Proliferating Cell Indices in Cerebral Gliomas. Cancer 74: 1921-1926, 1994

[17] Rutka TJ, Murakami M, Dirks PB: Role of glial filaments in cells and tumors of glial origin: a review. J Neurosurgery 87: 420-430, 1997

[18] Shields R: Transition probability and the origin of variation in the cell cycle. Nature 267: 704-707, 1977

[19] Silbergeld DL, Rostomily RC, Alvord EC Jr: The cause of death in patients with glioblastoma is multifactoral: clinical factors and autopsy findings in 117 cases of supratentorial glioblastoma in adults. J Neurooncol 10:179-185, 1991

Figure legends:

FIG. 1. Schematic representation of the long-term videomicroscopy system. The incubator, placed on the inverted microscope's stage, holds the TC-dish. The microscope stage and the adequate cell culture conditions (temperature, atmosphere) are controlled by the computer. The CCD camera's images are transmitted to the computer, where the digitalized images can be processed and analysed or recorded on videotape.

FIG. 2. The growth of the normalized cell number in a given visual field. The y-axis is logarithmic, and the actual cell numbers were normalized by the $N_{0}$ coefficient of the exponential fit $N \sim N_{0} e^{\alpha t}$. The growth rate is similar in all the cell cultures investigated. The solid line shows the fitted exponential growth with the average duplication time $(\tau=38 \pm 4)$.

FIG. 3. The distribution of the cell-cycle time $\left(\tau_{0}\right)$. The distribution functions obtained from the three cell lines could not be distinguished statistically. Thus the proliferating cells in any of the investigated cultures divided with the similar cell-cycle time.

FIG. 4. The daughter cells' cell-cycle time $\left(\tau_{0}(d)\right)$ versus the parent cells' cell-cycle time $\left(\tau_{0}(p)\right)$. The scattering of the data points means that the cell-cycle times in the subsequent generations do not correlate.

FIG. 5. Snapshots from the recordings of the various cell lines. Despite the same diagnosis, morphological differences can be observed. The approximately epithelial morphology of $\mathrm{HC}$ (c) cells can be compared to the fibroblastic characteristics of HA (a) and HB (b) cells. Field of view is $740 \mu \mathrm{m} \times 560 \mu \mathrm{m}$.

FIG. 6. Cellular trajectories in the HB3 measurement. (a) During the first 24 hours the cells perform a persistent random walk. (b) In the second 24 hours, at a higher cell density, the cells show a spatially ordered migration with increased persistence length. Field of view is $740 \mu \mathrm{m} * 560 \mu \mathrm{m}$.

FIG. 7. Cell velocities fluctuate in time. In the figure 3 representative cells' velocities are plotted vs time for each cell line. For better visualisaton the consecutive curves are shifted vertically by $50 \mu \mathrm{m} / \mathrm{h}$.

FIG. 8. The distribution function $G(v)=1-F(v)$ of the cell velocities in the investigated cultures on linear-logarithmic plot. The linearity of the curves indicate that the cell velocities can be described by an exponential distribution. The graph also shows that $G(v)$ function reproducibly distinguish the three different cell lines.

FIG. 9. Distribution functions of the average velocities of individual cells. The average was calculated over the entire measurement period and the functions are normalized by the average velocities of the cultures. The curves are well fitted by the calculated gamma distribution suggesting a phenotypically homogeneous population with respect to the locomotory activity. In the inserted graph the mixed curve - data from two different cell lines - shows a significant difference from the calculated gamma function. 
TABLE I. The most important data of the cell cultures analyzed

\begin{tabular}{|c|c|c|c|c|c|c|}
\hline measurement & HA1 & $\overline{\mathrm{HA} 2}$ & $\overline{\text { HB3 }}$ & $\overline{\mathrm{HB} 4}$ & $\overline{\mathrm{HCO}}$ & $\overline{\mathrm{HC} 2}$ \\
\hline $\begin{array}{c}\text { date of } \\
\text { operation }\end{array}$ & $\begin{array}{c}1997 \\
\text { March }\end{array}$ & $\begin{array}{c}1997 \\
\text { March }\end{array}$ & $\begin{array}{c}1996 \\
\text { October }\end{array}$ & $\begin{array}{c}1996 \\
\text { October }\end{array}$ & $\begin{array}{c}1995 \\
\text { February }\end{array}$ & $\begin{array}{c}1995 \\
\text { February }\end{array}$ \\
\hline $\begin{array}{l}\text { age and sex } \\
\text { of patient }\end{array}$ & $\begin{array}{c}58 \mathrm{y} \\
\mathrm{f}\end{array}$ & $\begin{array}{c}58 y \\
f\end{array}$ & $\begin{array}{c}51 \mathrm{y} \\
\mathrm{m}\end{array}$ & $\begin{array}{c}51 \mathrm{y} \\
\mathrm{m}\end{array}$ & $\begin{array}{c}61 \mathrm{y} \\
\mathrm{f}\end{array}$ & $\begin{array}{c}61 \mathrm{y} \\
\mathrm{f}\end{array}$ \\
\hline passage & 7 & 8 & 45 & 47 & 103 & 107 \\
\hline $\begin{array}{c}\text { area of } \\
\text { observed } \\
\text { field }[\mathrm{mm}]^{2}\end{array}$ & 1.14 & 0.41 & 0.41 & 1.14 & 1.14 & 0.41 \\
\hline $\begin{array}{c}\text { initial cell } \\
\text { number }\end{array}$ & 55 & 27 & 61 & 110 & 93 & 33 \\
\hline $\begin{array}{c}\text { initial cell } \\
\text { density }[\mathrm{mm}]^{-2}\end{array}$ & 48 & 65 & 148 & 96 & 82 & 80 \\
\hline
\end{tabular}

TABLE II. The data on proliferation in the six measurements

\begin{tabular}{|l|c|c|c|c|c|c|r|}
\hline \hline measurement & HA1 & HA2 & HB3 & HB4 & HC0 & HC2 & average \\
\hline $\begin{array}{l}\text { average cell-cycle } \\
\text { time and its standard } \\
\text { deviation [h] }\end{array}$ & $24.2 \pm 6.6$ & $27.9 \pm 5.8$ & n.a. & $24.7 \pm 5.9$ & n. a. & $25.9 \pm 5.9$ & $25.6 \pm 6.2$ \\
\hline duplication time[h] & 39,6 & 33,8 & 42,0 & 40,77 & 43.1 & 33,8 & $38 \pm 4$ \\
\hline $\begin{array}{l}\text { rate of non- } \\
\text { proliferating cells }\end{array}$ & $39 \%$ & n.a. & n.a. & $24 \%$ & n.a. & $30 \%$ & $32 \pm 5 \%$ \\
\hline \hline
\end{tabular}

TABLE III. The average velocities in the six measurements

\begin{tabular}{|l|c|r|r|r|r|r|}
\hline \hline measurement & HA1 & HA2 & HB3 & HB4 & HC0 & HC2 \\
\hline$V[\mu \mathrm{m} / \mathrm{h}]$ & 11,01 & 9,19 & 15,6 & 18,6 & 4,2 & 6,4 \\
\hline$v_{0}[\mu \mathrm{m} / \mathrm{h}]$ & 11,6 & 11,1 & 15,6 & 17,2 & 6,5 & 0,7 \\
\hline error $[\mu \mathrm{m} / \mathrm{h}]$ & 1,2 & 1,1 & 1,6 & 1,7 & 0,7 \\
\hline \hline
\end{tabular}




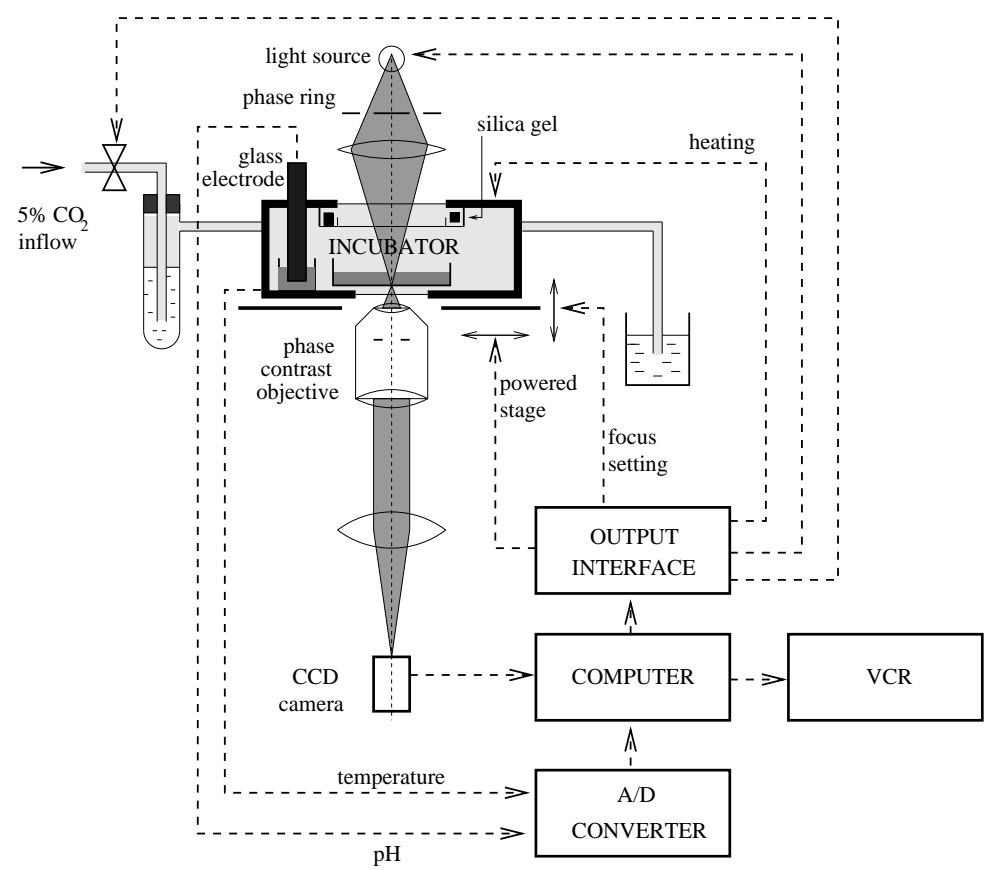




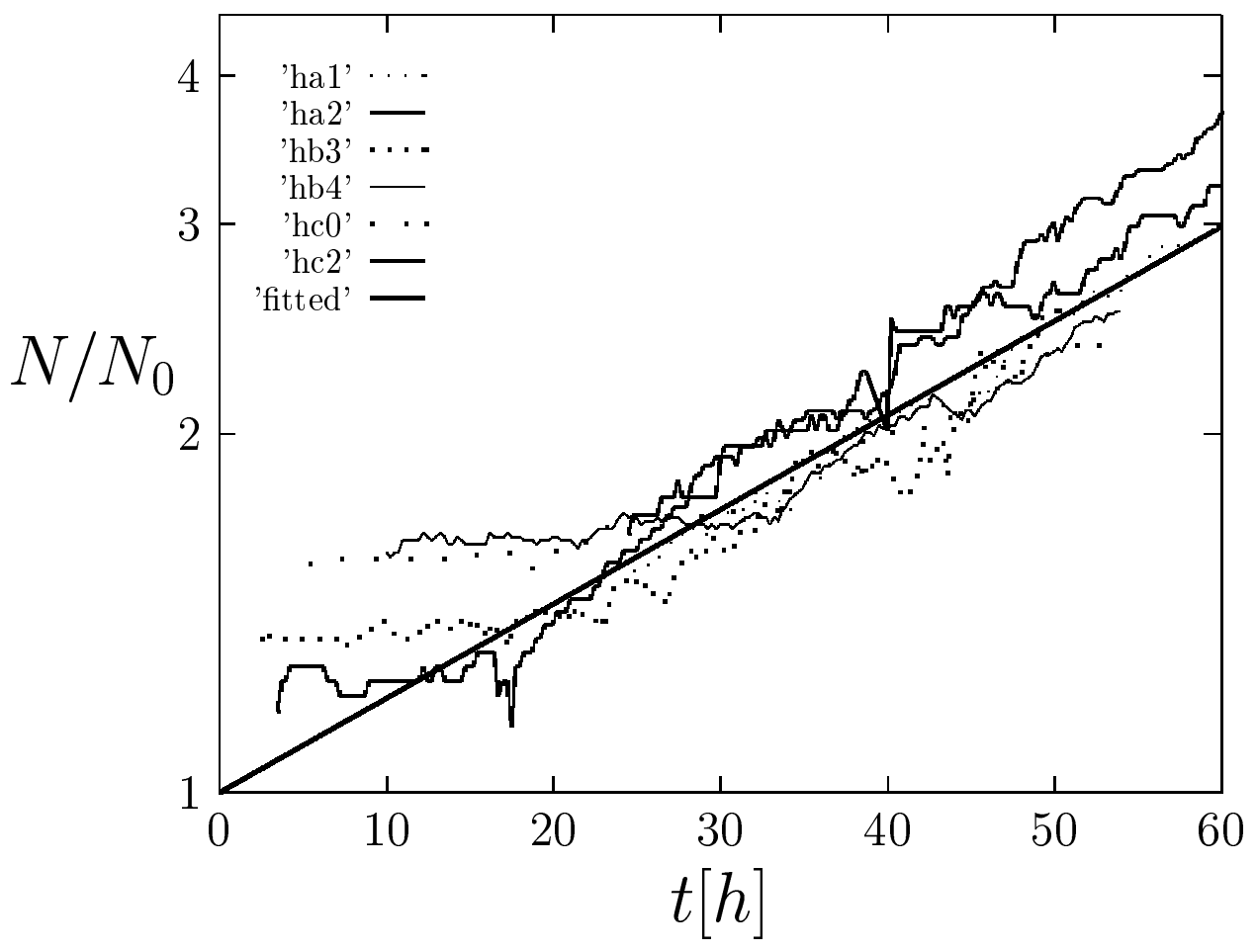




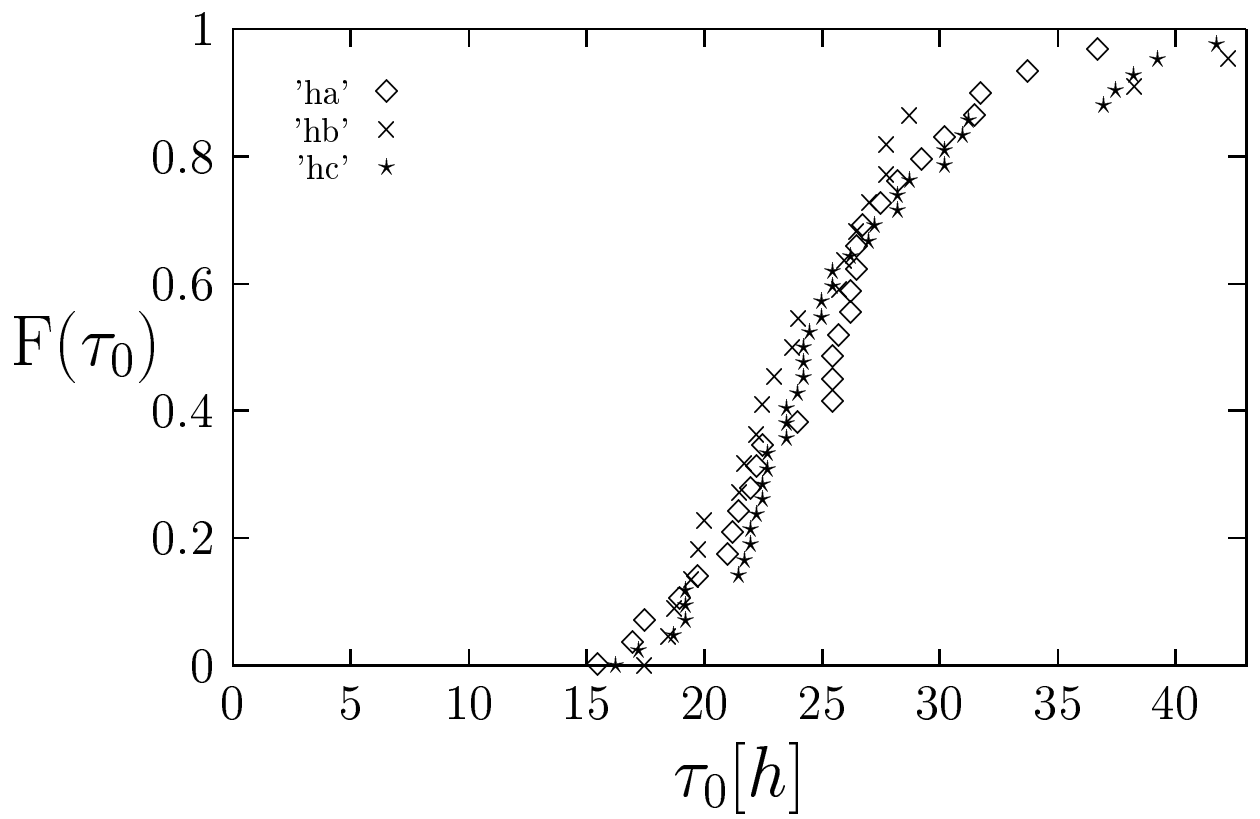




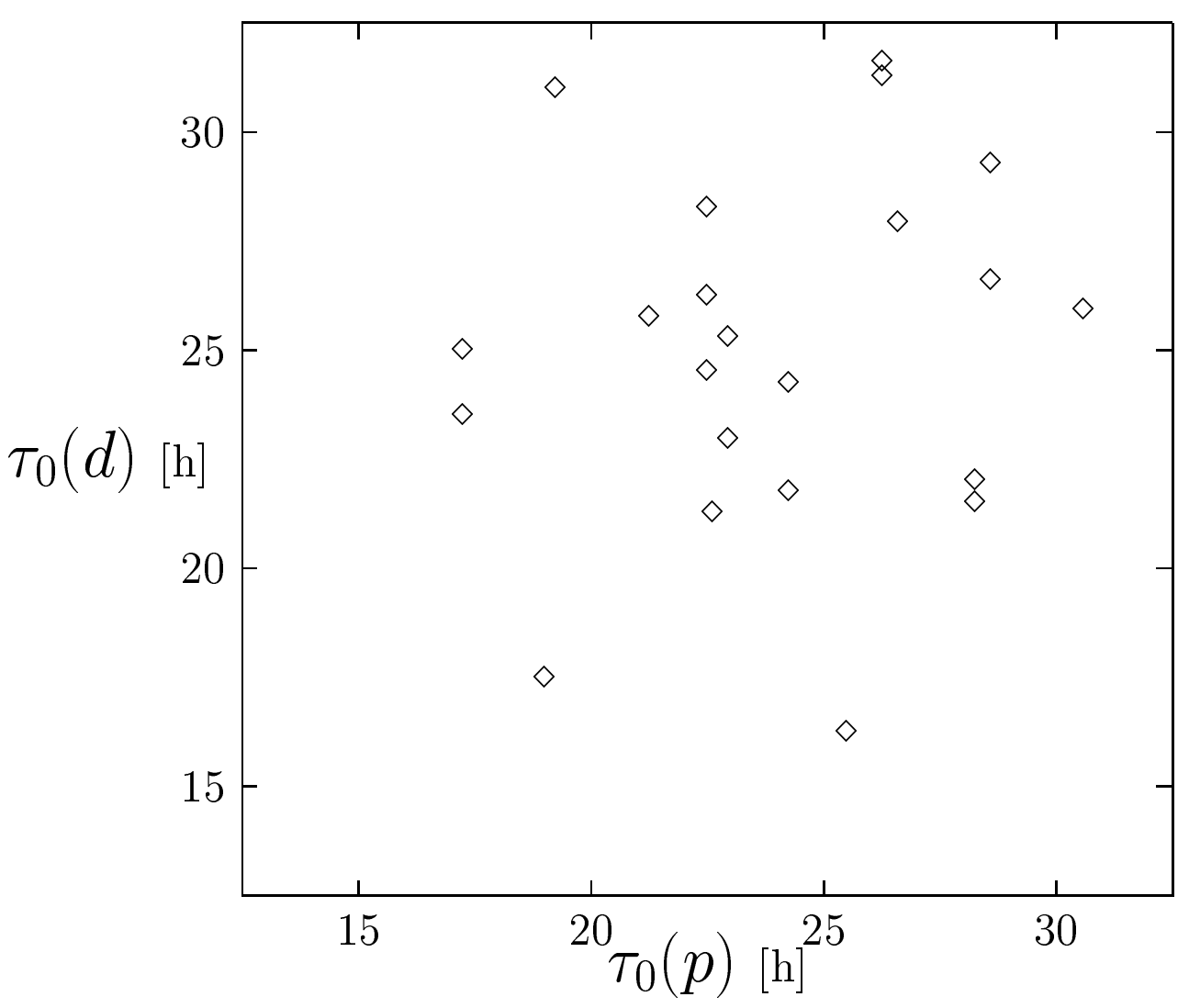



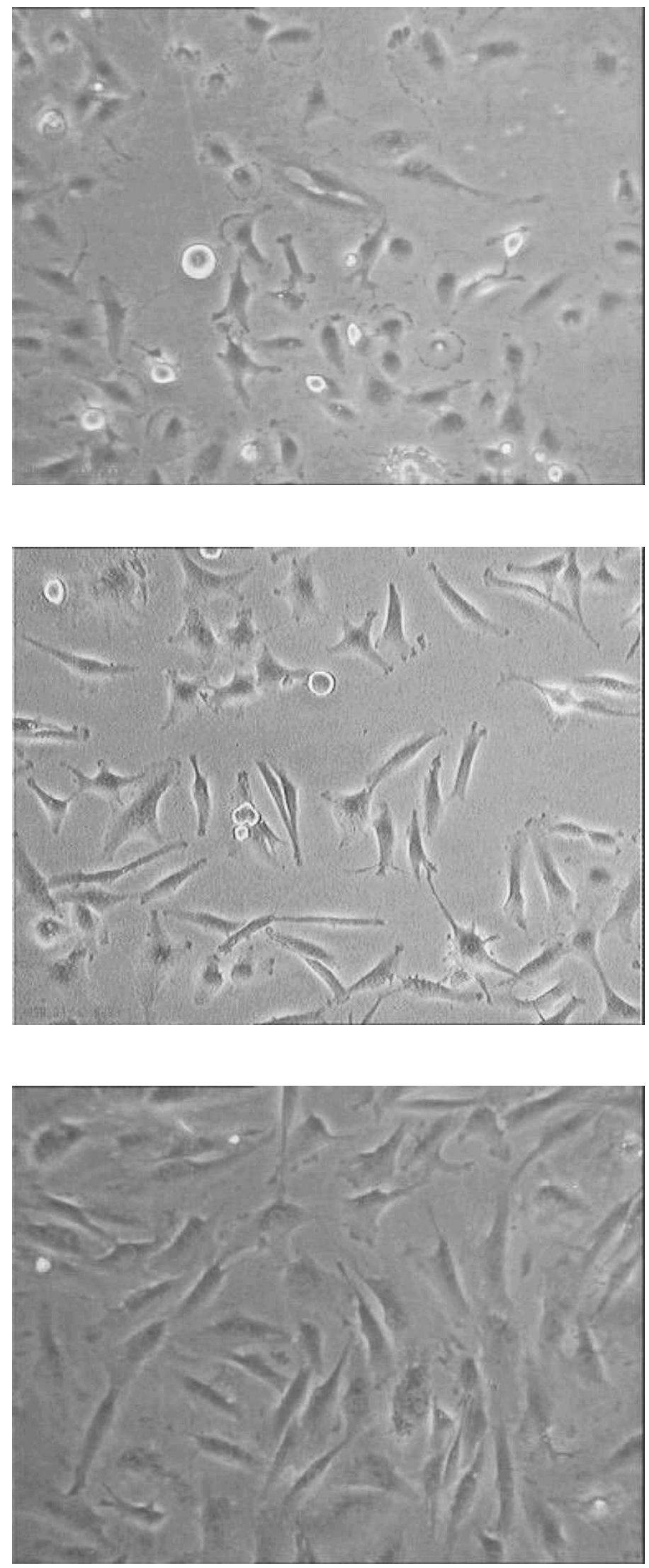

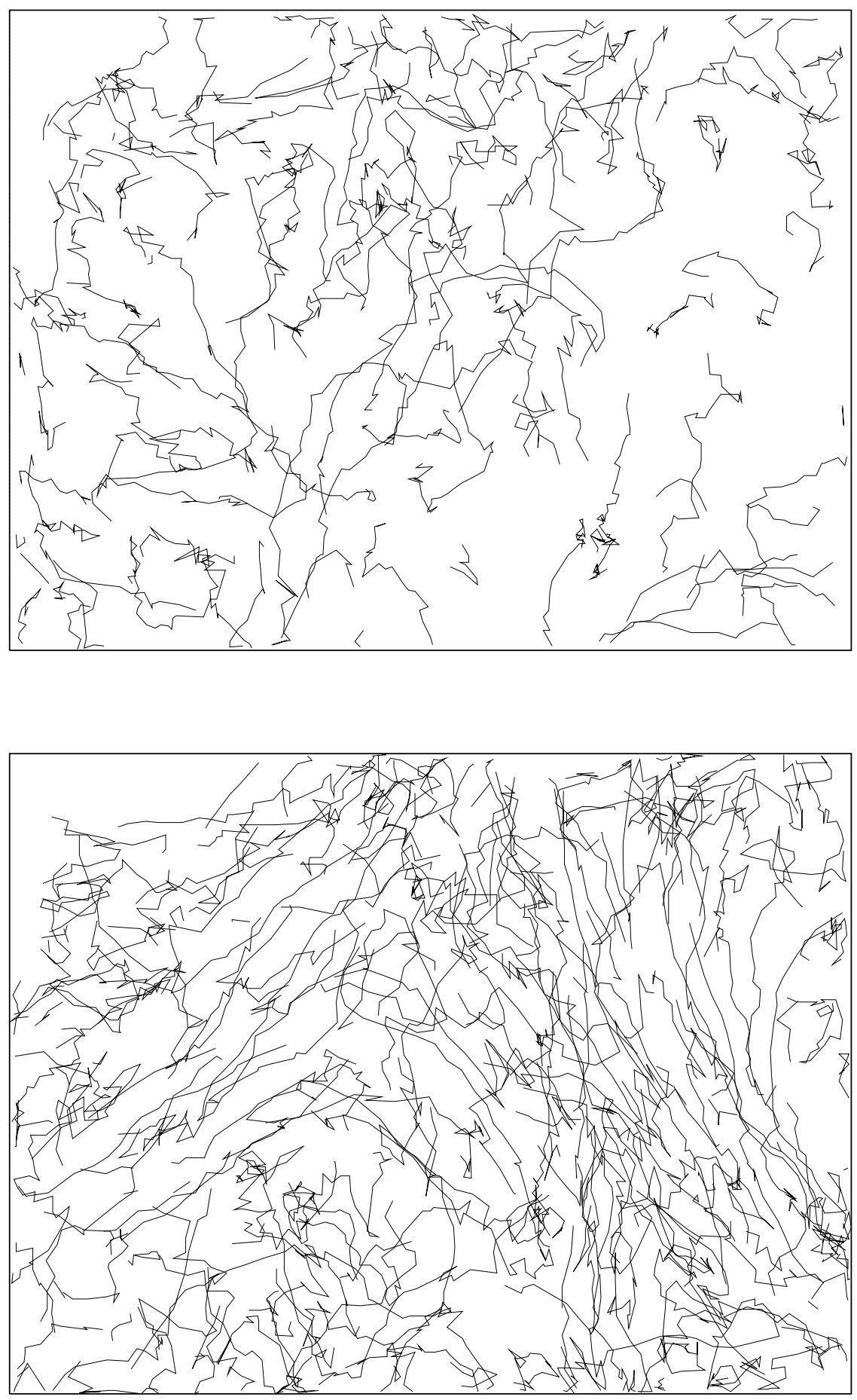


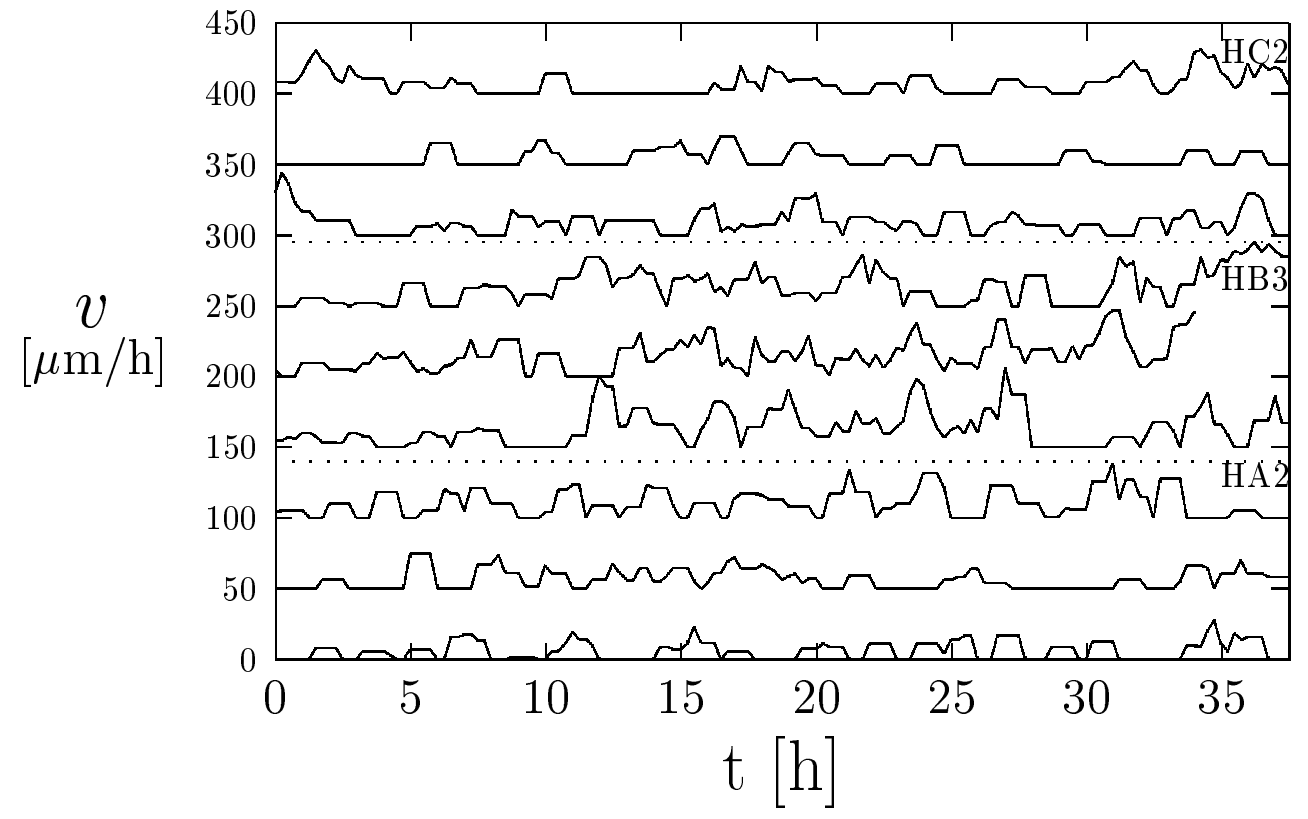




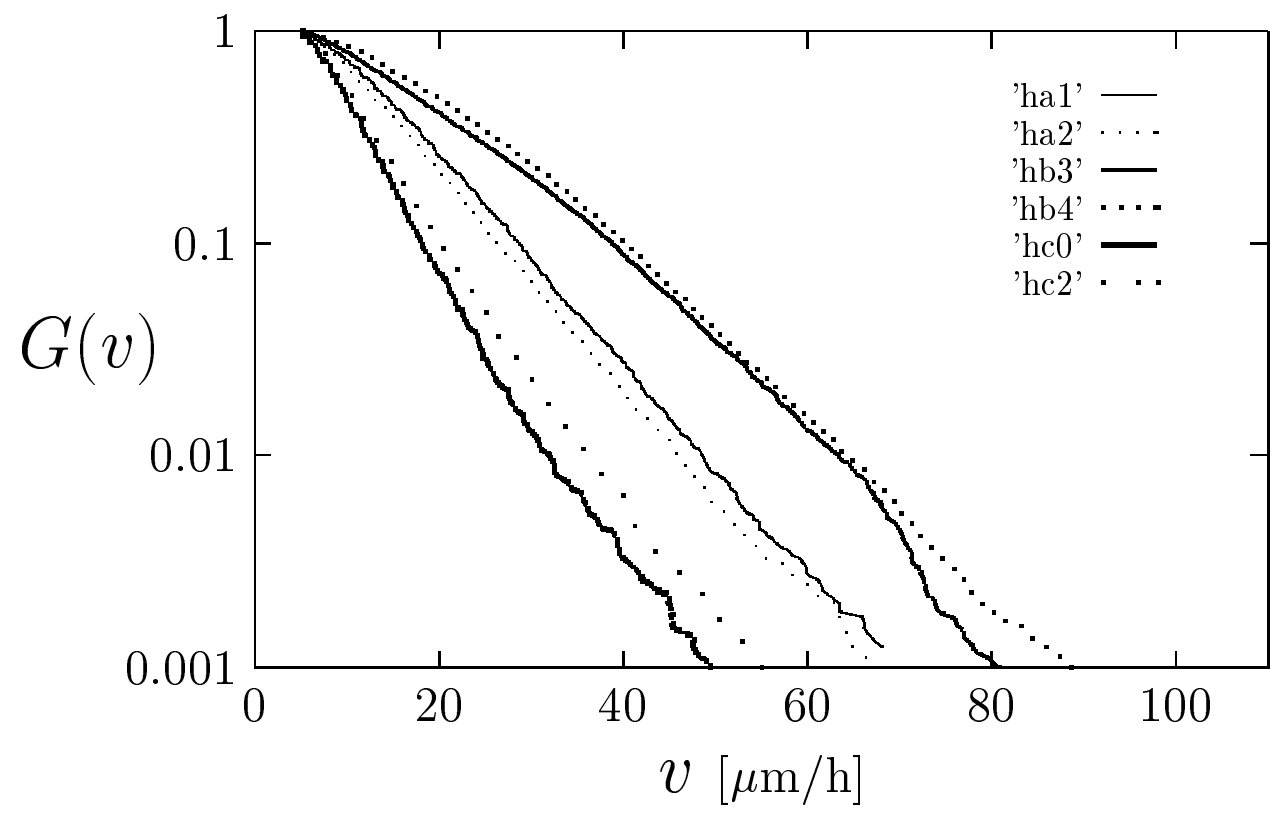




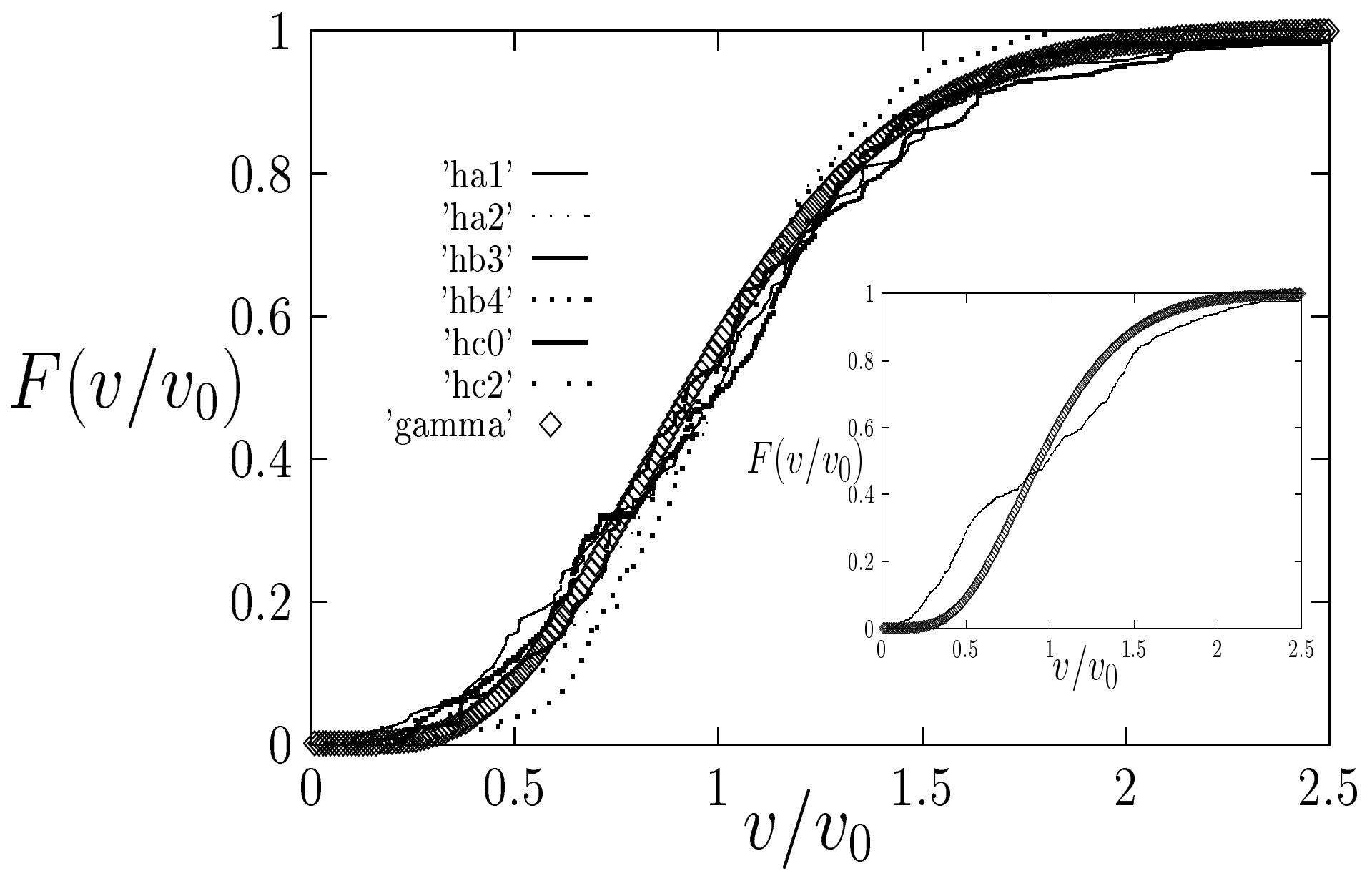

